\title{
Interdisciplinary Thinking and Physics Identity
}

\author{
Tyler D. Scott, Zahra Hazari and Geoff Potvin
}

\author{
Department of Engineering and Science Education, Clemson University, Clemson, SC 29634
}

\begin{abstract}
One goal of education is to help students become well-rounded citizens who can think broadly across boundaries. In addition, individuals with interdisciplinary thinking skills can be valuable contributors to modern research challenges by understanding and recognizing interdisciplinary connections and working in diverse teams. However, little research exists on the connection between interdisciplinary thinking and physics education. What aspects of physics classroom practices and experiences foster interdisciplinary thinking? What effect does interdisciplinary thinking have on the development of students' physics identities? Using a physics identity theoretical framework with data from a national survey, this study found that self-reported characteristics of interdisciplinary thinking are significantly correlated with higher levels of physics identity development. Also, several factors of the physics classroom environment and pedagogies are significantly related to interdisciplinary thinking.
\end{abstract}

Keywords: Interdisciplinarity, Physics Identity, Pedagogy PACS: 01.20.Cc, 01.40.Fk, 01.40.G-

\section{INTRODUCTION}

Interdisciplinary thinking has been recognized as vital to the future of science and engineering in the United States $[1,2]$. Physics in particular is full of interdisciplinary research opportunities (e.g. biophysics and geospace physics). However, physics is sometimes thought of as monolithic with practitioners having few interests besides cloistering in a lab. For example, studies have found that students perceive physics as allowing few opportunities to form and express one's own ideas [3]. It is in the interests of the physics community to attract interdisciplinary thinking students and to develop characteristics of interdisciplinary thinking in its classrooms.

For this study, we use a physics identity framework. Physics identity is a way of understanding how someone perceives themselves with respect to the field of physics. We build on the work of Hazari et al. [4], which built on the framework of Carlone and Johnson [5]. Carlone and Johnson identified performance, competence, and recognition as factors influencing scientists' science identities. Hazari et al. [4] added an interest component to build a quantitative physics identity indicator that was used in a study of large-scale survey data. The interest dimension of physics identity encompasses the student's desire and enjoyment in learning the subject (physics in this case). Performance and competence describes the student's beliefs of their abilities to do well in class and understand content respectively. Recognition is the extent to which students believe their family, friends, and teachers see them as a "physics person." Follow-up research using this identity framework with Structural Equation Modeling has found that only recognition and interest have a direct impact on identity while performance/competence has an indirect effect through recognition and interest [6]. Thus, in this paper we focus on recognition and interest to develop our physics identity measure. It is important to remember that though these are separate factors influencing physics identity, they are related to each other. Also, physics identity is related to the student's larger identities.

Since physics identity describes how a person identifies with physics and is highly correlated with the choice of physics as a career [4], it is useful to understand what experiences, attitudes, and characteristics are related to identifying with physics. This study is guided by two research questions:

Q1. Are students' reports of interdisciplinary interest and ability (interdisciplinary thinking) related to their physics identity?

Q2. What pedagogical and environmental characteristics of the physics classroom are related to interdisciplinary thinking?

We begin by describing the dataset we obtained from a nationally administered survey and the analysis we performed. We then present the results of two linear models designed to answer our research questions. Finally, we discuss the results and suggest future work.

\section{METHODS}

This study draws from survey data obtained as part of the Sustainability and Gender in Engineering (SaGE) project (NSF Grant No. 1036617). The data used for this study come from surveys administered in introductory English courses at 50 colleges and universities to obtain 
a nationally representative sample of 6,772 responses. The institutional response rate was $100 \%$ (all colleges and universities that agreed to participate did so). English classes were selected to get a cross section of the US college population including both STEM and non-STEM majors. The survey included questions to probe students' attitudes towards science, math, and engineering; their high school experiences; their family and demographic backgrounds; and their career interests and expectations.

The analysis for this paper centers on questions pertaining to students' physics identity, interdisciplinary thinking characteristics, and high school physics classroom experiences and environment. Physics identity and interdisciplinary thinking items are based on students' level of agreement (on an anchored five-point scale) with relevant statements. The physics classroom items are a mixture of anchored five-point scale and categorical responses.

The physics identity indicator for this study was constructed from recognition and interest factors. The recognition factor consists of responses to "My parents/relatives/friends see me as a physics person" and "My physics teacher sees me as a physics person." The interest factor consists of responses to "I am interested in learning more about this subject" and "I enjoy learning about this subject."

Our interdisciplinary thinking indicator is built from responses to "I hope to gain general knowledge across multiple fields" and "I identify relationships between topics from different courses." We chose these items because this type of "integration of disciplinary insights" has been found to be an essential characteristic of interdisciplinarity [7]. As with our physics identity indicator, this measure centers on self-reported beliefs of interest and ability. Similar to much other work in affect [8], it is reasonable to assume that such beliefs are an important pre-condition for the development of interdisciplinary skills.

For this study, data analysis was carried out with $\mathrm{R}$ version 3.0.0 [9]. We began by selecting only surveys in which the respondent indicated attendance in a high school physics class via a reported grade. Using the Amelia II package [10], we used multiple imputation of the other missing data to obtain a sample size of 2,066. We then built linear models applicable to our research questions using the Zelig package [11]. For the first model, we used our physics identity indicator as an outcome with controls of demographics, family variables, and several classroom related items that we determined were strong, significant predictors of physics identity. For predictors, we included our interdisciplinary thinking indicator and other "ways of thinking" items that were asked on the SaGE survey. The latter probed students' agreement with statements about the nature and value of science (both generally and personally) and perspectives on problem solving. These attitudes and beliefs could potentially complement or compete with our interdisciplinarity measure. Therefore we included them to obtain a more complete model. The natures of these items are explored further in the discussion section.

To answer the second question, we used our interdisciplinary thinking indicator as the outcome. For controls, we included demographic and family information. For predictors, we included various classroom pedagogy and environmental factors. These were students' reports of what their high school physics classroom were like. As with other educational outcomes, we expect the classroom environment and teachers' pedagogical methods to influence (for good or ill) the development of interdisciplinarity. We used a hierarchical regression approach (starting with controls) to build the model and checked the reliability of the model using a backward elimination approach. The resulting model was the same in both cases.

For all linear models, we used an $\alpha=0.01$ significance threshold to reduce the chance of type I error.

\section{RESULTS AND DISCUSSION}

A summary of our first linear regression model probing the link between interdisciplinary thinking and physics identity is shown in Table 1. Results show our interdisciplinary thinking indicator is a significant, positive predictor of physics identity. Since the SaGE dataset also included math identity items, for comparison we related students' interdisciplinary thinking to their math identity as well. The results were not significant. This is important because it indicates the relationship between interdisciplinary thinking and physics identity is not just because interdisciplinary thinkers have broad interests that happen to include physics. If that were the case, we would expect interdisciplinary thinkers to have higher identities in many academic fields including mathematics. Evidently, there is something about physics that attracts interdisciplinary thinkers in ways that mathematics, for example, does not.

The reason for this interdisciplinary attraction of physics might be that physics as an academic subject is often not introduced to students until near the end of their high school careers. In contrast, mathematics is something that all students learn in classes devoted to the subject from their earliest years. Therefore, students have well developed ideas of what math is, what it means to do math, and whether it relates to how they see themselves. On the other hand, physics is something new that offers a fresh pursuit to the interdisciplinary thinker, who has a broad range of interests. It is also possible that these students recognize a broad reach in physics and connections with many other disciplines. 
TABLE 1. Regression model predicting physics identity ( $N=2066)$. $* *: p<0.01$; $* * *: p<0.001$; ns: not significant.

\begin{tabular}{|c|c|c|c|c|}
\hline Parameter & Est. & Std. Err. & $\beta$ & Signif. \\
\hline Intercept & -1.74 & 0.12 & & $* * *$ \\
\hline \multicolumn{5}{|l|}{ Controls } \\
\hline Race, ethnicity, and SES & & & & ns \\
\hline Physics grade & 0.09 & 0.01 & 0.15 & $* * *$ \\
\hline Family science hobbies & 0.24 & 0.05 & 0.09 & $* * *$ \\
\hline Father/male guardian is a scientist & 0.38 & 0.16 & 0.07 & $* * *$ \\
\hline Gender $(0=$ Female, $1=$ Male $)$ & 0.51 & 0.04 & 0.21 & $* * *$ \\
\hline Physics class topics were relevant to their life & 0.08 & 0.02 & 0.08 & $* * *$ \\
\hline Physics teacher explained ideas clearly & 0.04 & 0.01 & 0.05 & $* *$ \\
\hline Interest of fellow students in physics class & 0.24 & 0.02 & 0.25 & $* * *$ \\
\hline \multicolumn{5}{|l|}{ "Ways of thinking" predictors } \\
\hline Interdisciplinary thinking indicator & 0.11 & 0.03 & 0.07 & $* * *$ \\
\hline "Learning science will improve my career prospects" & 0.11 & 0.03 & 0.12 & $* * *$ \\
\hline $\begin{array}{l}\text { "Science has helped me see opportunities for positive } \\
\text { change" }\end{array}$ & 0.18 & 0.03 & 0.16 & $* * *$ \\
\hline "The scientific method always leads to correct answers" & 0.07 & 0.02 & 0.07 & $* *$ \\
\hline
\end{tabular}

The two predictors, "Learning science will improve my career prospects" and "Science has helped me see opportunities for positive change," are defined by Godwin et al. [12] as components of personal science agency beliefs (what one believes that science can do at a personal level). Students who perceive science as being useful to them identify with physics more than those who do not. These agency beliefs are related to, but are distinct from, students' epistemological beliefs. The final significant predictor in this model is an epistemological belief that the scientific method "always leads to correct answers". Again, this is not surprising as high school students perceive physics as heteronomous [3].

Table 2 is a summary of the second model showing significant links between the physics classroom and interdisciplinary thinking. We found two of our included controls were significant (family perception of science improving career prospects and English scores). It is not surprising that high English scores are related to interdisciplinary thinking. We would expect interdisciplinary students to have strong language and communication skills [13]. Furthermore, language and communication are the foundation of education. Broad interests and the ability to connect topics are highly dependent on a student's general ability to understand and process information whether in printed or auditory form.

Among the pedagogy and classroom environment predictors, five predictors were significant. An interesting result is that doing problems requiring several steps of calculations is positively and significantly related with interdisciplinary thinking. A problem with several steps, when well written, requires the ability to synthesize information and apply connections between different concepts to solve the problem. This is something that inter- disciplinary thinkers may be good at and is a tool that teachers might be able to use to help foster interdisciplinary thinking in their students.

The other significant, positive predictors in this model are discussing topics relevant to the student's life, spending time doing individual work, focusing on conceptual understanding, and the teacher's enthusiasm for physics. Real-life relevance and conceptual understanding in particular are discussed in literature as being linked to interdisciplinary education $[14,15]$. Teacher enthusiasm could stimulate in students a general love of learning that becomes interdisciplinary interest. In general, most of these classroom characteristics may indicate a good classroom experience, which in turn is good for interdisciplinary thinking. In other words, these experiences may make it easier for students to engage with the topics, make connections for themselves, and cultivate new interests.

\section{CONCLUSIONS AND FUTURE WORK}

It is important to remember the analyses presented here using cross-sectional data can establish correlational relationships, not causal ones. However, it is clear that characteristics of interdisciplinary thinking are significantly related to the development of physics identity. This is in contrast to mathematics identity for which there is apparently no significant relationship. This could be due to the late introduction of physics into the high school experience. A way to test this might be to explore the connection between interdisciplinary thinking and physics identity among students in a "physics first" curriculum compared to those in a traditional high school 
TABLE 2. Regression model predicting interdisciplinary thinking $(\mathrm{N}=2066)$. ${ }^{*}: \mathrm{p}<0.01 ; * * *: \mathrm{p}<0.001$; ns: not significant.

\begin{tabular}{|c|c|c|c|c|}
\hline Parameter & Est. & Std. Err. & $\beta$ & Signif. \\
\hline Intercept & 1.61 & 0.09 & & $* * *$ \\
\hline \multicolumn{5}{|l|}{ Controls } \\
\hline Race, ethnicity, and SES & & & & ns \\
\hline Family saw science as a way to have a better career & 0.17 & 0.03 & 0.10 & $* * *$ \\
\hline English scores ${ }^{\dagger}$ & 0.43 & 0.09 & 0.10 & $* * *$ \\
\hline \multicolumn{5}{|l|}{ Physics classroom factors } \\
\hline Spent time doing individual work in class & 0.06 & 0.02 & 0.07 & $* * *$ \\
\hline Topics were relevant to their life & 0.04 & 0.01 & 0.08 & $* *$ \\
\hline Level of conceptual understanding required & 0.06 & 0.02 & 0.07 & $* *$ \\
\hline Questions required several steps of calculations & 0.11 & 0.04 & 0.06 & $* *$ \\
\hline Teacher's enthusiasm for physics & 0.06 & 0.01 & 0.12 & $* * *$ \\
\hline Adjusted $\mathrm{R}^{2}=0.09$ & & & & \\
\hline
\end{tabular}

$\dagger$ A composite of class grades and standardized test scores.

program. However, a "physics first" curriculum might also do a better job at revealing the interdisciplinary connections of physics.

Several physics classroom pedagogy and environmental factors were found to be significantly and positively related to interdisciplinary thinking characteristics. Some are related to the teacher's ability to exude enthusiasm and foster interest in their students. Other pedagogyspecific factors were related to an effective classroom that fosters independence, synthesis, and conceptual understanding. This work lends support to claims that conceptual understanding and real-life relevance are linked to interdisciplinarity. Future work should focus on examining the causal link between these particular pedagogies and interdisciplinary thinking. What do these links look like in the classroom? What does a good multi-step problem look like? Are some forms of independent work better than others at developing interdisciplinary thinking?

Finally, future work should focus on developing better models of interdisciplinary thinking. The interdisciplinary thinking indicator used in this study was constructed of only two items that cover the most obvious characteristics of interdisciplinary thinking. Future work should explore other characteristics that should be included in a more robust model.

\section{ACKNOWLEDGMENTS}

This material is based on work supported by the National Science Foundation under Grant No. 1036617. Any opinions, findings, conclusions, or recommendations expressed in this material are those of the authors and do not necessarily reflect the views of the National Science Foundation. The authors would also like to thank the SaGE team including Leidy Klotz, Robynne Lock, Allison Godwin, and Jennifer Cribbs, and the many par- ticipants in this study.

\section{REFERENCES}

1. National Science Foundation, Investing in America's Future: Strategic Plan 2006-2011, Tech. rep., National Science Foundation (2006).

2. C. M. Vest, The Bridge 36, 38-44 (2006).

3. U. Kessels, M. Rau, and B. Hannover, The British Journal of Educational Psychology 76, 761-80 (2006), ISSN 0007-0998.

4. Z. Hazari, G. Sonnert, P. M. Sadler, and M. C. Shanahan, Journal of Research in Science Teaching 47, 978-1003 (2010), ISSN 00224308.

5. H. B. Carlone, and A. Johnson, Journal of Research in Science Teaching 44, 1187-1218 (2007).

6. J. Cribbs, Z. Hazari, P. M. Sadler, and G. Sonnert, "Development of an Explanatory Framework for Mathematics identity," in Proceedings of the Psychology of Mathematics Education - North America (PME-NA) Chapter Conference, Kalamazoo, MI, 2012, pp. 335-338.

7. V. Boix Mansilla, and E. Dawes Duraising, The Journal of Higher Education 78, 215-237 (2007).

8. A. Bandura, Self-efficacy: The exercise of control, Freeman, New York, 1997.

9. R Core Team, R: A Language and Environment for Statistical Computing (2013), URL http: //www.r-project.org/.

10. J. Honaker, G. King, and M. Blackwell, Journal of Statistical Software 45, 1-47 (2011).

11. I. Kosuke, G. King, and O. Lau, Journal of Computational and Graphical Statistics 17, 892-913 (2008).

12. A. Godwin, G. Potvin, and Z. Hazari, "The Development of Critical Engineering Agency, Identity, and the Impact on Engineering Career Choices," in 120th ASEE Annual Conference \& Exposition, Atlanta, GA, 2013.

13. M. Borrego, and L. K. Newswander, The Review of Higher Education 34, 61-84 (2010), ISSN 1090-7009.

14. H. G. Petrie, Review of Research in Education 18, 299-333 (1992).

15. W. H. Newell, New Directions for Teaching and Learning 58, 35-51 (1994), ISSN 0271-0633. 